\title{
Mapping possible flowpaths of contaminants through surface and cross-borehole spectral time-domain induced polarization
}

\author{
Thue Bording \\ Department of Geoscience \\ Aarhus University \\ C.F. Mфllers Allé 4, 8000 Aarhus $C$ \\ thue.bording@geo.au.dk
}

\section{Esben Auken}

Department of Geoscience

Aarhus University

C.F. Møllers Allé 4, 8000 Aarhus C esben.auken@geo.au.dk

\author{
Gianluca Fiandaca \\ Department of Geoscience \\ Aarhus University \\ C.F. Mфllers Allé 4, 8000 Aarhus C \\ gianluca.fiandaca@geo.au.dk
}

\section{Anders Vest Christiansen \\ Department of Geoscience \\ Aarhus University \\ C.F. Møllers Allé 4, 8000 Aarhus C anders.vest@geo.au.dk}

\author{
Pradip Kumar Maurya \\ Department of Geoscience \\ Aarhus University \\ C.F. Møllers Allé 4, 8000 Aarhus C \\ pradip.maurya@geo.au.dk
}

\begin{abstract}
SUMMARY
Traditional methods for mapping possible flowpaths of contaminants in sedimentary environments by boreholes may often be insufficient. Additional information may be acquired by geophysical methods. In the present study, cross-borehole and surface measurements were performed using time-domain induced polarization (TDIP). After measurements the entire test site was dug out, and the geology was described.
\end{abstract}

A 2D spectral inversion of the combined dataset is presented, which is in great correspondence with the observed geology.

Key words: Time-domain, induced polarization, Crosshole tomography

\section{INTRODUCTION}

In the Capitol Region of Denmark, several sites are contaminated due to various human activities. A large fraction of these sites are in clayey moraines, where the flow of pollutants predominantly occurs in sand lenses or sandy layers. Boreholes are normally drilled in order to describe the geology, but boreholes alone do not always provide the necessary resolution to map out such sand lenses, which is why the Capitol Region initiated a project to evaluate different cross-borehole geophysical methods for mapping sand lenses/layers. A test site was established in an uncontaminated gravel pit near Hedehusene, Zeeland, Denmark (Kallerup grusgrav).

Our contribution was with spectral time-domain induced polarization (Fiandaca et al., 2012, 2013), due to its capability in lithotype discrimination (e.g. Chongo et al., 2015; Gazoty et al., 2012), while other research groups performed georadar and seismic cross-borehole acquisitions.
After measurements the entire test site was dug out, and the geology was described and compared to the geophysical results.

\section{METHOD AND RESULTS}

Field Site

The test site was in gravel pit near Hedehusene, Zeeland, Denmark (Kallerup grusgrav). Here, the sand and gravel are primarily extracted from the Hedeland Fm., which is overlain by $6-10 \mathrm{~m}$ of moraine. A few thin sand layers are observed in the moraine. The water table at the site was below 20 meters.

\section{Data Acquisition}

The measurements were carried out late in 2015. The electrode array consisted of a NE-SW oriented surface profile with three boreholes. The surface profile was $63 \mathrm{~m}$ long with an electrode spacing of $1 \mathrm{~m}$. The boreholes were drilled at the $6.35 \mathrm{~m}, 12.15 \mathrm{~m}$ and $17.20 \mathrm{~m}$ positions along the surface profile (Figure 1), with 50, 45 and 47 electrodes, respectively. Custom made tubes fitted with circular electrodes, with a vertical spacing of $20 \mathrm{~cm}$, were inserted in each borehole, and the boreholes were backfilled with sand and watered. The contact resistances measured in the boreholes just after the borehole installation were in the order of a few $\mathrm{k} \Omega$, but after a few hours they increased to tens of $\mathrm{k} \Omega$, due to the drainage of the water in the Hedeland Fm. at the bottom of the boreholes (the water table being well below the borehole depth). Test TDIP acquisitions with borehole sequences showed poor data quality due to the high contact resistance. Consequently, around 100 liters of salt water were poured in each borehole, resulting in a permanent decrease of contact resistance in the $\mathrm{k} \Omega$ range.

In total ten data sequences were collected: one using only the surface electrodes; three using electrodes in a single boreholes; three using electrodes in two boreholes; three using electrodes in two boreholes together with surface electrodes. The measurements were performed using the ABEM Terrameter LS, with $100 \%$ duty cycle, 4 seconds on-time and 3 pulses.

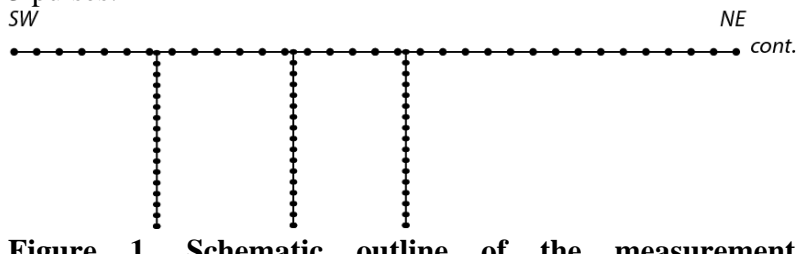

Figure 1. Schematic outline of the measurement configuration 


\section{Processing and inversion}

The IP decays were retrieved from the on-time of the $100 \%$ duty cycle measurements re-gating, stacking and normalizing the full waveform recordings $(3750 \mathrm{~Hz}$ sampling rate) as described in Olsson et al. (2015). Furthermore, the full waveform data were processed for removing spikes, background drift and harmonic noise following Olsson et al. (2016). The IP decays were further manually processed using Aarhus Workbench (Auken, 2009), for removal of apparent resistivity outliers and disturbed IP decays.

Figure 2 and 3 show some exemplary IP decays from the acquisitions carried out before and after the salt water injection. There is a clear improvement in data quality in the data acquired after the salt water injection, when much smaller contact resistances were measured, with almost one decade gained at early times and a smaller amount of spurious decays. Unfortunately, the added salt water significantly altered the resistivity distribution in the borehole surroundings. This is clear in Figure 4, where the 1D direct current (DC) inversions of borehole data before and after saltwater injection are compared.

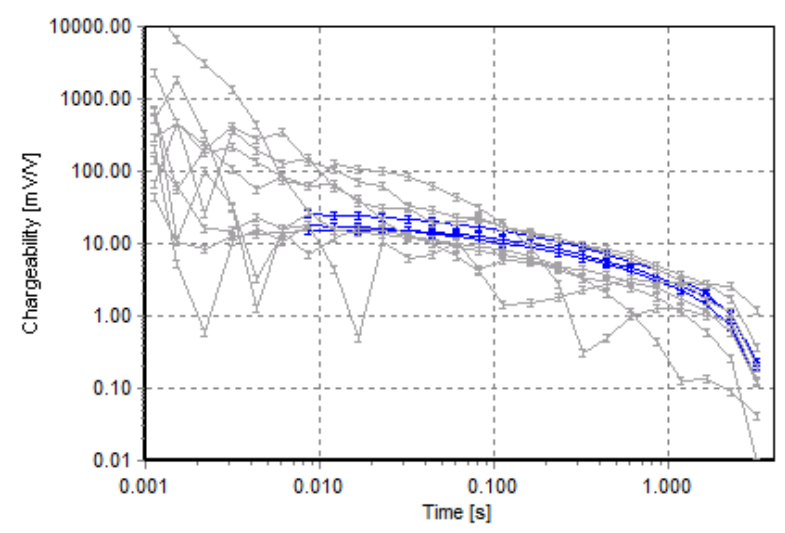

Figure 2. Exemplary IP decays before adding saltwater

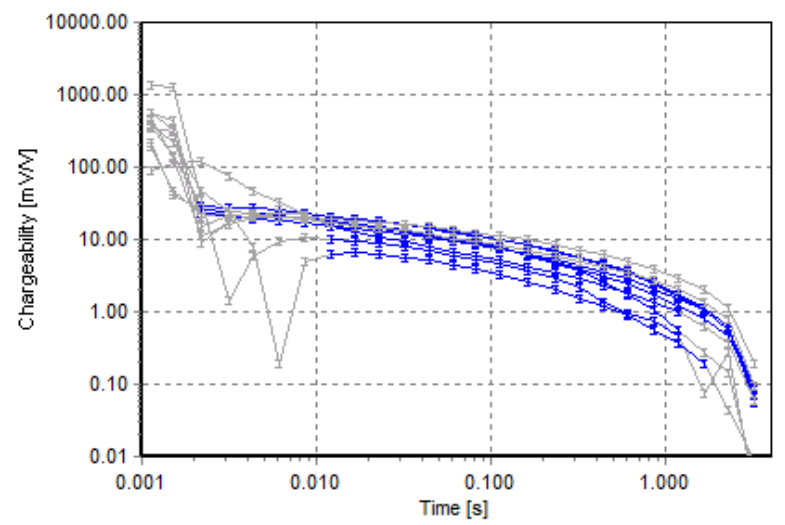

Figure 3. IP decays (same quadrupoles of Figure 2) after adding saltwater in the boreholes.
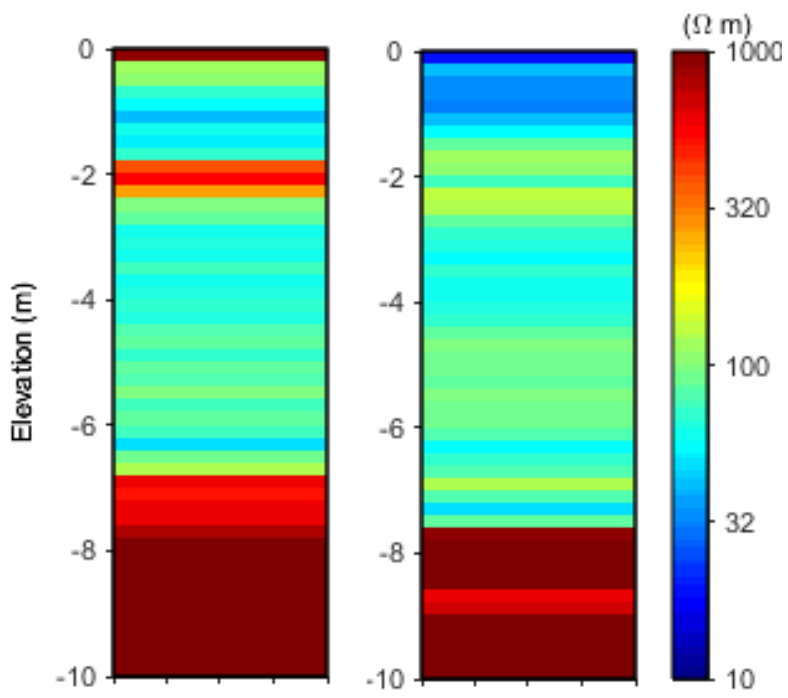

Figure 4. 1D DC inversion of single borehole data before (left) and after adding saltwater (right). Borehole 12.15.

Data were inverted using the 2D TDIP inversion code developed by Fiandaca et al. (2013), modified for allowing buried electrodes. This inversion routine inverts the full IP decays and apparent resistivity values, taking into account transmitter waveform and receiver transfer function, to retrieve the four Cole-Cole parameters (Pelton et al., 1978), namely resistivity $(\rho)$, chargeability $\left(\mathrm{m}_{0}\right)$, relaxation time $(\tau)$ and frequency exponent $(\mathrm{C})$.

The inversion results are shown in Figure 5 (last page). A connected resistive sand layer is seen to be present at $2 \mathrm{~m}$ depth. The top of a highly resistive layer is seen 6-7 $\mathrm{m}$ below the surface, which corresponds to the Hedeland Fm.. Layering is clearly visible in the moraine till between $2 \mathrm{~m}$ and $7 \mathrm{~m}$, with the DC and IP parameters suggesting the presence of several clay-rich thin layers. The overall geology has been confirmed by the excavation performed for verifying the geophysical results.

\section{CONCLUSIONS}

DC resistivity and TDIP measurements were carried out in a cross-borehole setup at a test site, for mapping possible flowpaths of contaminants. Data were processed for harmonic de-noising, background removal and de-spiking from the full waveform acquisition, resulting in a first usable gate as early as 2 milliseconds. This was achieved also decreasing the contact resistance at the electrodes pouring saltwater in the boreholes, because the water table was deeper than the boreholes themselves. With the saltwater addition almost one decade at early times was gained, but the resistivity distribution in the borehole surroundings was altered. Despite of the alterations in the parameter distributions close to the boreholes, it was possible to retrieve correctly the distribution of sand lenses/layers at the site, as confirmed by the excavations carried out for verifying the geophysical results.

\section{ACKNOWLEDGMENTS}

The authors are thankful to the Capitol Region of Denmark for funding the project under which the present study has been carried out. 


\section{REFERENCES}

Auken, E., A. Viezzoli, and A. V. Christiansen, 2009, A Single Software For Processing, Inversion, And Presentation Of Aem Data Of Different Systems: The Aarhus Workbench, Adelaide, ASEG.

Chongo M., Christiansen A.V., Fiandaca G., Nyambe I.A., Larsen F. \& Bauer-Gottwein P., 2015. Mapping localised freshwater anomalies in the brackish paleo-lake sediments of the Machile-Zambezi Basin with transient electromagnetic sounding, geoelectrical imaging and induced polarisation, Journal of Applied Geophysics, 123, 81-92. 10.1016/j.jappgeo.2015.10.002.

Fiandaca, G., E. Auken, A. Gazoty, and A. V. Christiansen, 2012, Time-domain induced polarization: Full-decay forward modeling and 1D laterally constrained inversion of Cole-Cole parameters: Geophysics, v. 77, p. E213-E225.

Fiandaca, G., J. Ramm, A. Binley, A. Gazoty, A. V. Christiansen, and E. Auken, 2013, Resolving spectral information from time domain induced polarization data through 2-D inversion: Geophysical Journal International, v. 192, p. 631-646.
Gazoty, A., G. Fiandaca, J. Pedersen, E. Auken, and A. V. Christiansen, 2012, Mapping of landfills using time-domain spectral induced polarization data: The Eskelund case study: Near Surface Geophysics, v. 10, p. 575-586.

Olsson P.-I., Dahlin T., Fiandaca G. \& Auken E., 2015. Measuring time-domain spectral induced polarization in the on-time: decreasing acquisition time and increasing signal-tonoise ratio, Journal of Applied Geophysics, 123, 316-321. 10.1016/j.jappgeo.2015.08.009.

Olsson P.I., Fiandaca G., Larsen J.J., Dahlin T., Auken E., 2016. Doubling the spectrum of time-domain induced polarization: removal of non-linear self-potential drift, harmonic noise and spikes, tapered gating, and uncertainty estimation. 4th IP Workshop, 6-8 June 2016, Aarhus, Denmark.

Pelton, W. H., S. H. Ward, P. G. Hallof, W. R. Sill, and P. H. Nelson, 1978, Mineral discrimination and removal of inductive coupling with multifrequency IP: Geophysics, v. 43, p. 588-609. 

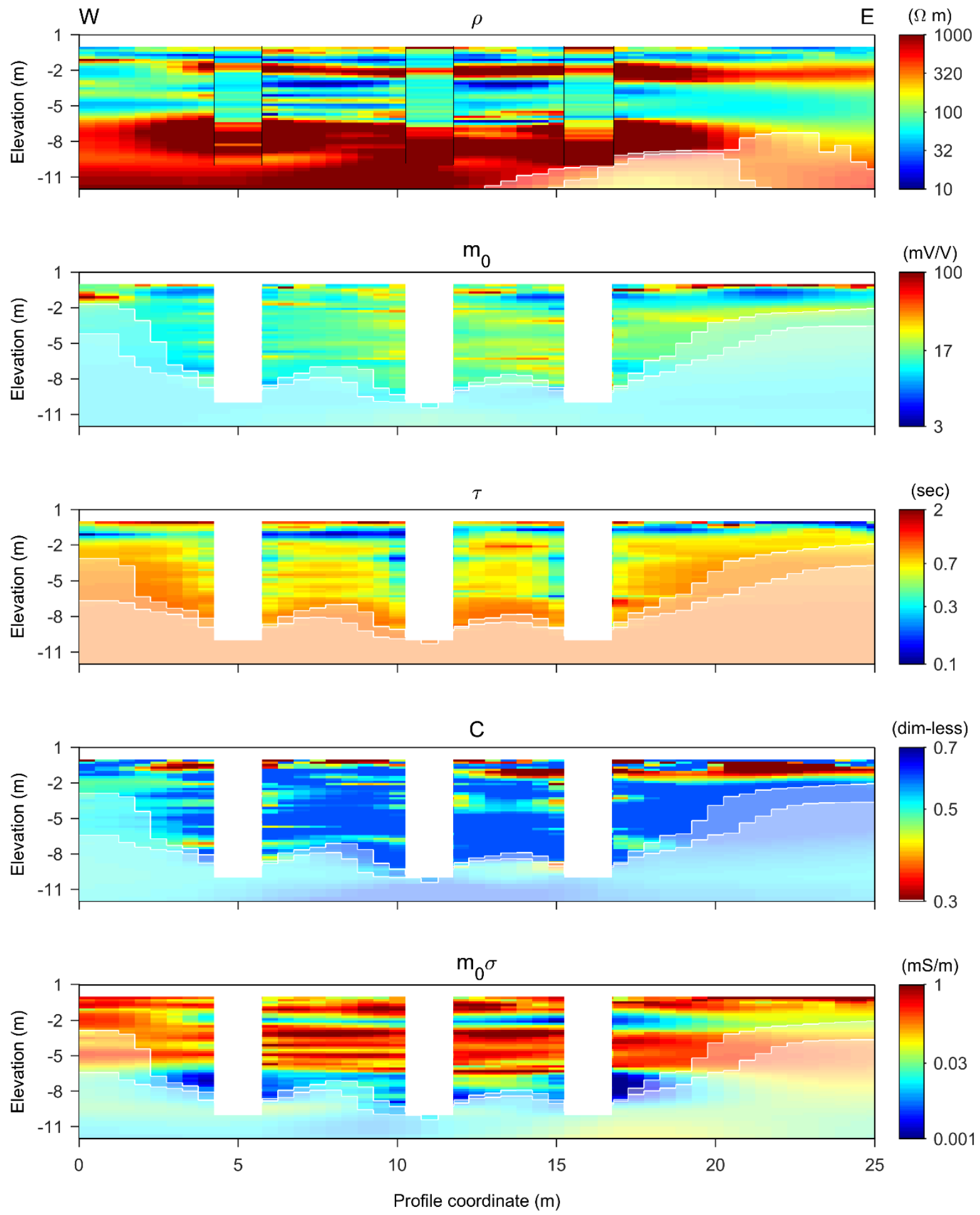

Figure 5. 2D TDIP inversion results. Shown here are resistivity $(\rho)$, chargeability $\left(\mathrm{m}_{0}\right)$, relaxation time $(\tau)$, frequency exponent $(C)$ and normalized chargeability $\left(\mathrm{m}_{0} / \rho\right)$. The model cells in the borehole surroundings are blanked out, for masking the saltwater effect and simplify the readability of the figure. In the resistivity section, instead of masking the cells in the borehole surroundings, the 1D DC inversion models retrieved from borehole-only data before adding saltwater are superposed to the cross-borehole inversion model. 